\title{
Developing the New Interventions for independence in Dementia Study (NIDUS) theoretical model for supporting people to live well with dementia at home for longer: a systematic review of theoretical models and Randomised Controlled Trial evidence
}

\author{
Kathryn Lord ${ }^{1}$. Jules Beresford-Dent ${ }^{1} \cdot$ Penny Rapaport ${ }^{2} \cdot$ Alex Burton $^{2} \cdot$ Monica Leverton $^{2} \cdot$ Kate Walters $^{3}$. \\ lain Lang ${ }^{4} \cdot$ Murna Downs $^{1}$. Jill Manthorpe ${ }^{5} \cdot$ Sue Boex ${ }^{6} \cdot$ Joy Jackson $^{6} \cdot$ Margaret Ogden $^{6} \cdot$ Claudia Cooper $^{2}$ (I)
}

Received: 25 March 2019 / Accepted: 9 October 2019 / Published online: 2 November 2019

(c) The Author(s) 2019

\begin{abstract}
Purpose To build an evidence-informed theoretical model describing how to support people with dementia to live well or for longer at home.

Methods We searched electronic databases to August 2018 for papers meeting predetermined inclusion criteria in two reviews that informed our model. We scoped literature for theoretical models of how to enable people with dementia to live at home independently, with good life quality or for longer. We systematically reviewed Randomised Controlled Trials (RCTs) reporting psychosocial intervention effects on time lived with dementia at home. Two researchers independently rated risk of bias. We developed our theoretical model through discussions with experts by personal, clinical and academic experiences, informed by this evidence base.

Results Our scoping review included 52 studies. We divided models identified into: values and approaches (relational and recovery models; optimising environment and activities; family carer skills and support); care strategies (family carer-focused; needs and goal-based; self-management); and service models (case management; integrated; consumer-directed). The 11 RCTs included in our systematic review, all judged at low risk of bias, described only two interventions that increased time people with dementia lived in their own homes. These collectively encompassed all these components except for consumerdirected and integrated care. We developed and revised our model, using review evidence and expert consultation to define the final model.

Conclusions Our theoretical model describes values, care strategies and service models that can be used in the design of interventions to enable people with dementia to live well and for longer at home.

Trial registration PROSPERO 2018 registration number: CRD42018099693 (scoping review).

PROSPERO 2018 registration number: CRD42018099200 (RCT systematic review).
\end{abstract}

Keywords Dementia $\cdot$ Home care $\cdot$ Theoretical models

\section{Introduction}

Around 46.8 million people worldwide have dementia, and this is expected to increase to 131.5 million by 2050 [1]. Two-thirds of people diagnosed with dementia live in their own homes [2] and most want to continue to do so, as independently as possible [3]. Remaining at home benefits the

Claudia Cooper

Claudia.cooper@ucl.ac.uk

Extended author information available on the last page of the article individual with dementia, through greater quality of life, and society, by reducing costs of care [2]. It is unclear which care models enable this most effectively and equitably, and promote development of the "Dementia friendly, dementia capable, and dementia positive" services and communities, to which most developed countries aspire [4, 5]. Good quality community care should be accessible to all people living with dementia. Hospitalisation or nursing home admission of people with dementia may reflect inequities in availability of community care. Risks of care breakdown and hospitalisation are high in people living with dementia [6], especially 
for people with greater cognitive, functioning and behavioural care needs; and who are cared for by family carers reporting high stress levels [7]. Living well with dementia has been conceptualised as living with quality of life, choice, autonomy, dignity and as independently as possible. There can be a tension between independence as an expression of full autonomy [8] and the interdependence that can enable people with dementia to live in their own homes for longer [9].

To inform future interventions and selection of outcome measures to evaluate them, we aimed to build a theory and evidence-based model to explain how people living with dementia can be supported to live as full a life as possible at home. To inform our model, we: (a) scoped literature for existing theoretical models of how to enable people with dementia to live at home more independently, with good life quality or for longer; and (b) systematically reviewed Randomised Controlled Trials (RCTs) to identify psychosocial interventions that effectively extended time lived with dementia outside $24 \mathrm{~h}$ care settings. Experts by experience, clinical or academic knowledge used this evidence to develop a new theoretical model.

\section{Methods}

\section{Search strategies and selection criteria}

We undertook searches in August 2018, without limits to language or publication date. We registered reviews (PROSPERO: CRD42018099693/9200).

\section{Scoping review of theoretical models}

We used standard scoping review methodology [10]. Inclusion criteria were broad, encompassing: studies, reviews, reports and chapters describing a theoretical or conceptual model, developed from expert consensus, sociological theory or primary research. We included models that explained how people can live well with dementia in their own homes, with greater independence, life quality or for longer. JBD searched Medline/PubMed and OVID. Search terms related to dementia (dementia, Alzheimer's, memory loss, memory disorder, cognitive impairment), community (community care, community residing, home, private dwelling, sheltered housing), independence (autonomy, freedom, self determination, independent, living well, quality of life) and theories/ models and concepts (theory, theoret*, model, concept). CC removed duplicates, screened electronic search results, hand searched included papers' references, and searched careinfo. org, and google scholar using similar terms. CC also search the journal Dementia: the international journal of social science research as a volume of particular relevance to the topic, that has published many papers describing theoretical models underpinning dementia care delivery.

$\mathrm{KL}$ and $\mathrm{CC}$ read papers independently to identify models. An expert reference group (comprising CC, AB, PR, IL, SB, $\mathrm{MO}, \mathrm{JJ}, \mathrm{ML}$ (authors), an occupational therapist and memory service manager) reviewed preliminary results and suggested areas for further scoping: compassion and empathy. A further PubMed search using these terms and dementia yielded two additional papers.

\section{Systematic review of RCTs}

KL searched PubMed, Embase and PsycINFO using keywords: Dementia OR cognitive impairment AND home or community AND time OR length; filtering results to include Randomised Controlled Trials (RCTs) only; hand searched included papers' references and searched clinicaltrialsregiater.eu. We included RCTs evaluating nonpharmacological interventions reporting time a person with dementia lived at home as a primary or secondary outcome. We excluded studies if any participants lived in 24-h care at baseline; and conference abstracts.

We resolved uncertainties regarding study inclusion through discussion. We contacted experts to enquire about additional published or unpublished work. A second author crosschecked one tenth of abstracts from the original searches, and did not identify any additional eligible papers. $\mathrm{KL}$ and CC extracted data. We narratively synthesised findings. We did not formally assess publication bias as our study aims did not warrant this.

\section{Quality appraisal}

In line with the selected methodological approach, we did not formally evaluate study quality in our scoping review; but we recorded level of evidence (Table 1) [10]. For our systematic review of RCTs, KL and CC appraised study risk of bias independently, using an operationalized checklist developed by our group [11, 12]. Each checklist item scored one point, so five was the highest possible quality score. KL and CC discussed discrepancies to reach consensus. The authors decided a priori the checklist items that should be endorsed to define a study as lower risk of bias (denoted by $*$ below):

(1) Were participants appropriately allocated to intervention and control groups? (Was randomisation independent?)*

(2) Were patients and clinicians, as far as possible, 'masked' to treatment allocation?

(3) Were patients who entered the trial accounted for and intention-to-treat analyses used?* 
Table 1 Results of scoping review of publications proposing theoretical or conceptual models describing how people with dementia can be supported to live well or longer at home; showing model components identified and level of evidence

\begin{tabular}{|c|c|c|c|c|c|}
\hline \multirow[t]{2}{*}{ Study } & \multirow[t]{2}{*}{ Country } & \multicolumn{3}{|l|}{ Models proposed } & \multirow[t]{2}{*}{ Level of evidence } \\
\hline & & Values/approaches & Strategies & Service models & \\
\hline Amella et al. [43] & USA & & $\begin{array}{l}\text { 3P's social ecological } \\
\text { model }\end{array}$ & & Case studies \\
\hline Banerjee et al. [50, 51] & UK & Person-centred care & $\begin{array}{l}\text { Identify needs, carer } \\
\text { support, early inter- } \\
\text { vention }\end{array}$ & Case management & Service evaluation \\
\hline Beck et al. [44] & USA & & $\begin{array}{l}\text { Occupational therapy } \\
\text { models }\end{array}$ & & Expert opinion \\
\hline Behuniak [21] & USA & Political model & & & Expert opinion \\
\hline Brooker [16] & UK & VIPS framework & & & Expert opinion \\
\hline Brodaty et al. [36] & Australia & & $\begin{array}{l}\text { Carer-focussed strate- } \\
\text { gies }\end{array}$ & & $\begin{array}{l}\text { Randomised controlled } \\
\text { trial }\end{array}$ \\
\hline Bunn et al. [39] & UK & & $\begin{array}{l}\text { Carer-focussed strate- } \\
\text { gies }\end{array}$ & & $\begin{array}{l}\text { Systematic literature } \\
\text { review }\end{array}$ \\
\hline Cabin [48] & USA & & & Palliative care model & Expert opinion \\
\hline Cahill [23] & UK & Rights-based care & & & Expert opinion \\
\hline $\begin{array}{l}\text { Callahan et al., Boustani } \\
\text { et al., Callahan et al. } \\
{[33,67,68]}\end{array}$ & USA & Person-centred care & & Collaborative care & $\begin{array}{l}\text { RCT and Implementation } \\
\text { study }\end{array}$ \\
\hline Caron et al. [34] & Canada & Carer proxy decisions & & & Qualitative study \\
\hline Chung et al. [17] & UK & Agency and personhood & & & Qualitative study \\
\hline Daley et al. [26] & UK & $\begin{array}{l}\text { Recovery focused } \\
\text { model }\end{array}$ & & & Qualitative study \\
\hline Downs and Lord [13] & UK & Person-centred care & & & Expert opinion \\
\hline Evans et al. [60] & UK & & Increasing activities & $\begin{array}{l}\text { Supporting people } \\
\text { funding scheme }\end{array}$ & Expert opinion \\
\hline Gaugler et al. [40] & USA & & $\begin{array}{l}\text { Identify/prioritise } \\
\text { unmet needs }\end{array}$ & & $\begin{array}{l}\text { Longitudinal quantitative } \\
\text { study }\end{array}$ \\
\hline Goeman et al. [54] & Australia & & & Case management & $\begin{array}{l}\text { Systematic literature } \\
\text { review }\end{array}$ \\
\hline Graff [45] & Netherlands & Optimising environment & Goal-setting, carer skills & & Case study \\
\hline Gresham et al. [37] & Australia & & $\begin{array}{l}\text { Carer-focussed strate- } \\
\text { gies }\end{array}$ & & $\begin{array}{l}\text { Longitudinal quantitative } \\
\text { study }\end{array}$ \\
\hline Hoppes et al. [30] & USA & Ecological theory & & & Pilot quantitative study \\
\hline Hurley et al. [35] & UK & $\begin{array}{l}\text { Home safety/Injury } \\
\text { model }\end{array}$ & & & Qualitative study \\
\hline Khanassov et al. [55] & Canada & & & Case management & $\begin{array}{l}\text { Systematic literature } \\
\text { review }\end{array}$ \\
\hline Kohler et al. [59] & Germany & Person-centred care & $\begin{array}{l}\text { Self-management, } \\
\text { carer support, early } \\
\text { intervention }\end{array}$ & Collaborative care & $\begin{array}{l}\text { Randomised controlled } \\
\text { trial }\end{array}$ \\
\hline Kolanowski et al. [32] & USA & $\begin{array}{l}\text { Theories of neuroplas- } \\
\text { ticity }\end{array}$ & & & Evidence review \\
\hline Kontos [19] & Canada & $\begin{array}{l}\text { Phenomenological } \\
\text { model }\end{array}$ & & & Expert opinion \\
\hline Kovach [31] & USA & $\begin{array}{l}\text { Sensoristasis \& imbal- } \\
\text { ance }\end{array}$ & & & $\begin{array}{l}\text { Evidence review/expert } \\
\text { opinion }\end{array}$ \\
\hline Laakkonen et al. [46] & Finland & Self-management & & & $\begin{array}{l}\text { Randomised controlled } \\
\text { trial }\end{array}$ \\
\hline Lin \& Lewis [4] & USA & $\begin{array}{l}\text { Dementia friendly com- } \\
\text { munities }\end{array}$ & & & $\begin{array}{l}\text { Narrative literature } \\
\text { review }\end{array}$ \\
\hline Livingston [38] & UK & & $\begin{array}{l}\text { Carer-focussed strate- } \\
\text { gies }\end{array}$ & & $\begin{array}{l}\text { Randomised controlled } \\
\text { trial }\end{array}$ \\
\hline
\end{tabular}


Table 1 (continued)

\begin{tabular}{|c|c|c|c|c|c|}
\hline \multirow[t]{2}{*}{ Study } & \multirow[t]{2}{*}{ Country } & \multicolumn{3}{|l|}{ Models proposed } & \multirow[t]{2}{*}{ Level of evidence } \\
\hline & & Values/approaches & Strategies & Service models & \\
\hline Low and Fletcher [58] & Australia & & & $\begin{array}{l}\text { Integrated/consumer- } \\
\text { directed care }\end{array}$ & $\begin{array}{l}\text { Narrative literature } \\
\text { review }\end{array}$ \\
\hline $\begin{array}{l}\text { MacNeil Vroomen et al. } \\
\text { [56] }\end{array}$ & Netherlands & & & Case management & Cohort study \\
\hline Manthorpe et al. [8] & UK & Rights-based care & & & Expert opinion \\
\hline Martin et al. [47] & UK & & Self-management & & $\begin{array}{l}\text { Qualitative, conceptual } \\
\text { study }\end{array}$ \\
\hline McIntyre [15] & Canada & Person-centred care & & & $\begin{array}{l}\text { Case studies/expert } \\
\text { opinion }\end{array}$ \\
\hline Menne et al. [28] & UK & Continuity theory & & & Qualitative interviews \\
\hline Perkins et al. [27] & UK & $\begin{array}{l}\text { Recovery focused } \\
\text { model }\end{array}$ & & & Briefing paper \\
\hline Reilly et al. [52] & UK & & & Case management & Systematic review \\
\hline Renehan et al. [53] & Australia & $\begin{array}{l}\text { Relationship centred, } \\
\text { enablement, holistic, } \\
\text { accessible }\end{array}$ & & & $\begin{array}{l}\text { Systematic review and } \\
\text { qualitative }\end{array}$ \\
\hline Rothera et al. [14] & UK & Person-centred care & & & $\begin{array}{l}\text { Qualitative implementa- } \\
\text { tion study }\end{array}$ \\
\hline $\begin{array}{l}\text { Samus et al., Black et al. } \\
{[49,69]}\end{array}$ & USA & Person-centred care & $\begin{array}{l}\text { Systematically identify } \\
\text { needs, carer support }\end{array}$ & Case management & $\begin{array}{l}\text { Quantitative study \& } \\
\text { Pilot randomised con- } \\
\text { trolled trial }\end{array}$ \\
\hline $\begin{array}{l}\text { Schölzel-Dorenbos et al. } \\
\text { [41] }\end{array}$ & Netherlands & & Needs-based care & & $\begin{array}{l}\text { Narrative literature } \\
\text { review }\end{array}$ \\
\hline Smebye et al. [24] & Norway & Theories of autonomy & & & Qualitative case study \\
\hline $\begin{array}{l}\text { Smebye \& Kirkevold } \\
\text { [18] }\end{array}$ & Norway & $\begin{array}{l}\text { Relationship focussed } \\
\text { care }\end{array}$ & & & Qualitative study \\
\hline Thyrian et al. [53] & Germany & Person-centred care & & Case management & $\begin{array}{l}\text { Randomised controlled } \\
\text { trial }\end{array}$ \\
\hline Tranvag et al. [22] & Norway & Dignity-preserving care & & & Meta-synthesis \\
\hline Woodbridge et al. [29] & UK & $\begin{array}{l}\text { Press-competence } \\
\text { model }\end{array}$ & & & $\begin{array}{l}\text { Systematic literature } \\
\text { review }\end{array}$ \\
\hline Woods [9] & UK & $\begin{array}{l}\text { Concept: excess dis- } \\
\text { ability }\end{array}$ & & & Expert opinion \\
\hline Zwijsen et al. [20] & Netherlands & Theories of autonomy & & & $\begin{array}{l}\text { Systematic literature } \\
\text { review }\end{array}$ \\
\hline
\end{tabular}

(4) Were all participants followed up and data collected in the same way?*

(5) Was there a power calculation, based on our outcome of interest?

We followed PRISMA guidelines when reporting the review.

\section{Model development}

CC presented emerging evidence and an initial model draft to the expert reference group. The group considered evidence emerging from the two reviews to decide which components were included in the model. The group agreed the final model at a face to face meeting in September 2018, and although we held a subsequent period of consultation through email discussions, no further changes were suggested by the group or made after this meeting.

\section{Results}

\section{Theoretical models scoping review}

We included 52 studies (Fig. 1 shows search results). We list the models identified in Table 1 and described them below. We divided the identified models into (1) values and approaches; (2) strategies for delivering care, and (3) service models for delivering dementia care. 

for literature review of theoretical and explanatory models of how people with dementia can be supported to live well independently
Fig. 1 PRISMA Flow Diagram
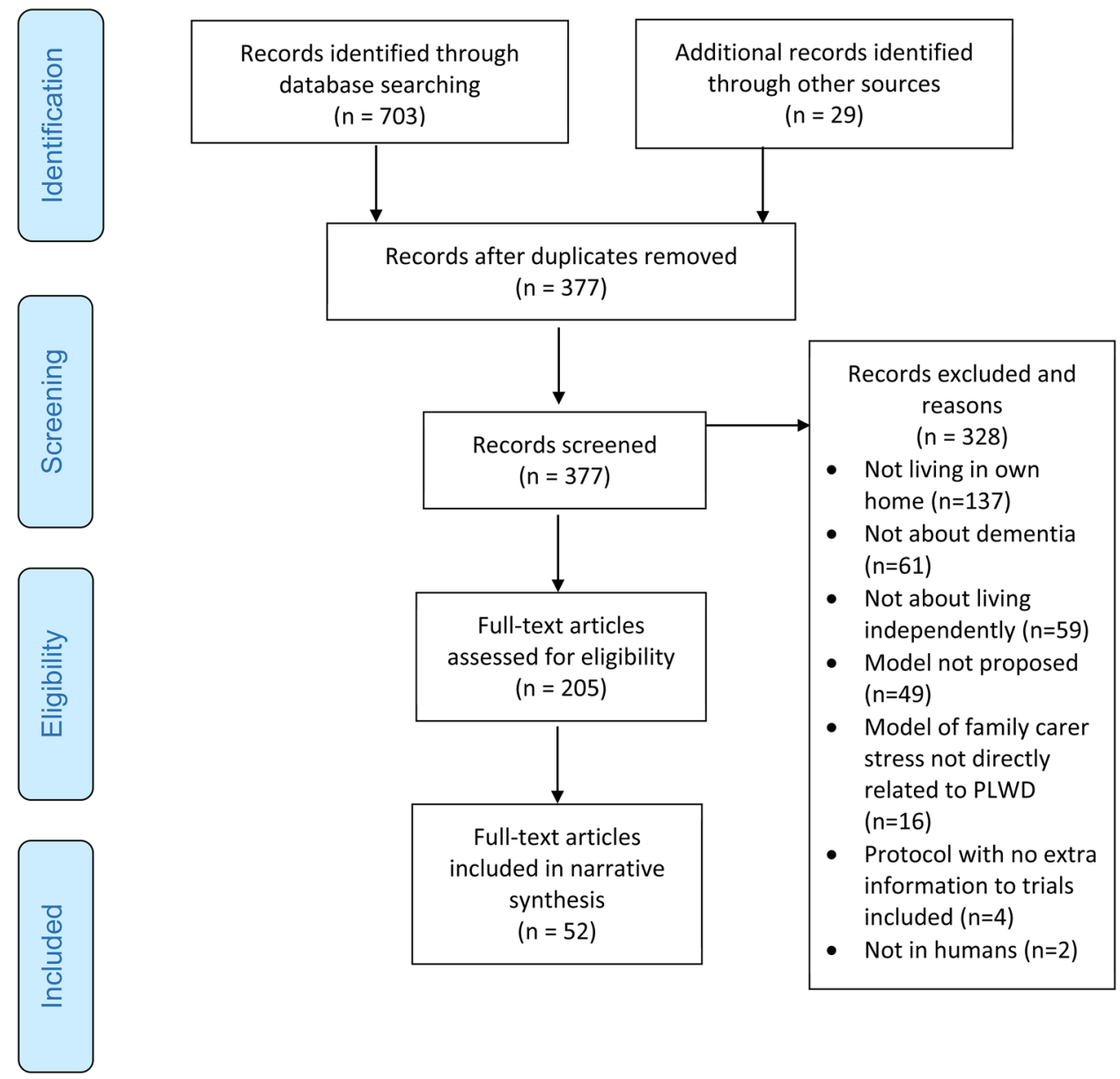

\section{Values and approaches}

These model components were reported in qualitative studies, evidence syntheses of predominantly qualitative studies, and expert opinion publications.

Relational and recovery models Kitwood is credited with introducing the biopsychosocial model of dementia care: now widely accepted, this posits that functioning in people living with dementia is not solely related to biological illness factors, but also their psychosocial environment [13]. His theory of person-centred care [14-16] argued that personhood, quality of life and well-being are a function of the quality of people's interactions and relationships. He described malignant social psychology (also termed malignant positioning by others), to refer to interactions that diminish a person's sense of belonging, personhood and self-worth. Person-centred care describes an individualised, humanistic care approach that promotes agency, choice and partnership in decision-making. Care consistent with this approach gives unconditional positive regard; facilitates a sense of worth; is risk tolerant; maintains the continuity of a person's identity; and provides opportunity for meaning- ful engagement and occupation. It is operationalised in the VIPS Framework (absolute Value of human lives; Individualised care; understanding the world from the Perspective of service users; Social environment that supports psychological needs) [16, 17].

Relationship-focussed care extends personhood theory to include inter-relatedness in caring relationships: mutuality and reciprocity [18]. Kontos' phenomenological model understands agency in people living with dementia as emanating from body (primordial and sociocultural characteristics residing below the threshold of cognition) as well as mind. It posits that people with dementia require respect as on-going although changed persons, who retain a sense of self and can form trusting relationships [19].

Rights-based models advocate for empowerment and engagement of people with dementia in dementia care [13]. Some political theories propose the need to accept the realities of interdependence in dementia care [20,21], and balance rights to autonomy, protection and good care [22, 23]. There may be trade-offs, for example between reduced privacy from technological surveillance and its potential to enable continued relative autonomy and attenuate risks of harm [24]. Advocating the person with dementia's autonomy 
and integrity is described as the foundation of dignity-preserving dementia care [25].

Recovery-focussed models in dementia conceptualise recovery as a journey that involves accommodating to diagnosis $[26,27]$. Continuity with pre-existing identity, networks, roles and activities can enable recovery. Taking personal responsibility is helpful to people living with dementia where possible; as dementia severity increases, there is a greater role for carers in supporting continuity with pre-existing identity. Menne et al. [28], in reporting findings from qualitative interviews with people living with early dementia, found that a desire to maintain continuity with previous ways of life emerged from narratives. They situated their findings in continuity theory.

Environmental and activity models Functional decline is influenced by the social and caregiving environment, which can induce or maintain "excess disability": for example, inactivity, boredom, and social withdrawal can compromise functioning [9]. Modifying the home environment can help maintain an individual's 'maximum performance potential' [29, 30]. Modifying the wider environment can promote Dementia-friendly communities [4]. Pacing activities optimally and matching sensory-stimulating and sensorycalming activities to the person with dementia's needs may prevent intrapsychic discomfort, agitation, and associated functional decline [31]. Physical activity and exercise may also stimulate neuroplasticity and increase cognitive reserve [32]. Callahan suggests these mechanisms are important in a restorative model of care [33].

Family carer-focussed models Family carer proxy decisionmaking regarding place of residence directly influences how long people live with dementia at home. Care recipient factors (degree of autonomy, dementia severity and capacity), context and care (support, environment and crises); family carer factors (other obligations, health, role meaning, emotions and help-seeking attitudes) determine their perceived ability to provide care, which they balance against anticipated consequences of moves to long-term care [34]. Carer self-efficacy, practical ability, values, traditions and resources will also influence their decisions that balance risks and benefits of people with dementia staying at home for longer [35].

\section{Strategies for delivering care}

There is at least one Randomised Controlled Trial (RCT) supporting efficacy of each of these broad categories.

Family carer-focussed interventions Have reduced carer burden and increased time lived at home by care recipients [36-38], probably because carers who are less stressed and burdened are more able to continue in supporting roles. UK Admiral Nursing Services work specifically with dementia family carers in some localities, but service content depends on local requirements and commissioning [39].

Needs and goals-based care Numerous models focus on identifying and prioritising needs, and/or setting goals to address them. People with dementia with fewer unmet needs live longer at home [40]. The Need-driven, Dementiacompromised Behaviour theory describes how unmet needs can lead to behaviours that challenge, increase carer burden, decrease life quality, and care breakdown. Scholzel-Dorenbos considered how needs might be prioritised, based on their likely impact on quality of life [41]. Goal Attainment Scaling is a method for identifying the unmet need with highest priority and setting goals to address it [42].

Other models guide responses to behavioural or functional needs, e.g. the 3P's model to change behaviour by considering "the Person, People (who are caring) and Place (environment)" [43]; and a framework to address functional needs, through strategies including stimulus control, verbal and physical prompts, modelling, and physical guidance [44]. In a case study, Graff described an Occupational Therapy (OT) treatment model in dementia combining education, goal-setting, environment adaptation, skills training for people with dementia or family carers, and addressing dysfunctional cognitions about patient behaviour and carer role [45].

Self-management models Position professionals as partners rather than experts and seek to enable self-efficacy in problem-solving [46, 47]. Beneficial effects on spousal quality of life and cognitive function of people with dementia have been reported [46].

\section{Dementia care service models}

Cabin contrasted medical and palliative care models that assume treatment is not curative. These include respite care, pastoral care, and volunteer services. Focus is on symptom management and quality of life [48].

Dementia case management (collaborative care/care coordination) In this service model, people living with dementia are allocated a care manager to coordinate care, facilitate collaboration between services and usually deliver care [49-53]. Dementia case management interventions have been associated with greater benefits for patient and carers if they are: for 6 months or more; multi-disciplinary, interprofessional, and delivered by a case worker with a skilled background (e.g. clinical or trained in dementia care) [54]. It may be more successful when more intensive (up to 50 clients per fulltime worker), with proactive and timely follow- 
up $[55,56]$. It should deliver relationship-based, holistic, enabling and accessible care [57]. The UK memory service model has a particular focus on early diagnosis and intervention; some memory services deliver case management, while many offer assessment and medication review [50, 51].

Integrated care models Aim to create connectivity, alignment and collaboration within services at funding, administrative or provider levels. This is different to, but may facilitate, case management approaches, where a case manager seeks to provide clients with integrated care by liaising with different services on their behalf. These approaches have been associated with fewer hospital days, and increased service use, but not life quality $[58,59]$. The UK Supporting People programme funded local authority-employed activity coordinators to support people with dementia living in their own homes to increase pleasant activities. By working across extra-care sheltered and private accommodation, that sought to promote community integration [60].
Consumer-directed care models Also termed personal budgets or direct payments in the English context, in these models the person living with dementia, or their proxy, decides which services or support to purchase. They increase service usage, satisfaction and costs in certain circumstances [58].

\section{Systematic review of RCTs}

Figure 2 shows our search results. We included 11 studies, all of which were rated as higher quality. Table 2 describes study characteristics and findings for included studies. We describe below the three studies (describing two interventions) that significantly increased time for people with dementia living at home.

The Maximizing Independence at Home (MIND) intervention delivers person-centred care with elements from all the "values and approaches" domains in our draft model: there is a focus on optimising environment and supporting family carers. Care is needs- and goal-based; needs are identified and mapped to a menu of care strategies including self-management strategies, carer-focussed
Fig. 2 PRISMA Flow Diagram for systematic review of RCT evidence of interventions to enable people with dementia to live longer in their own homes
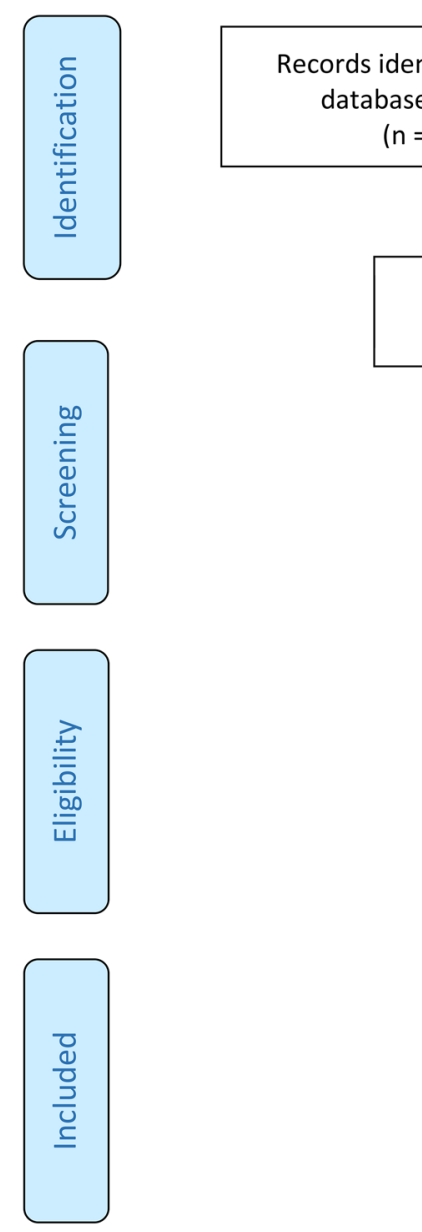


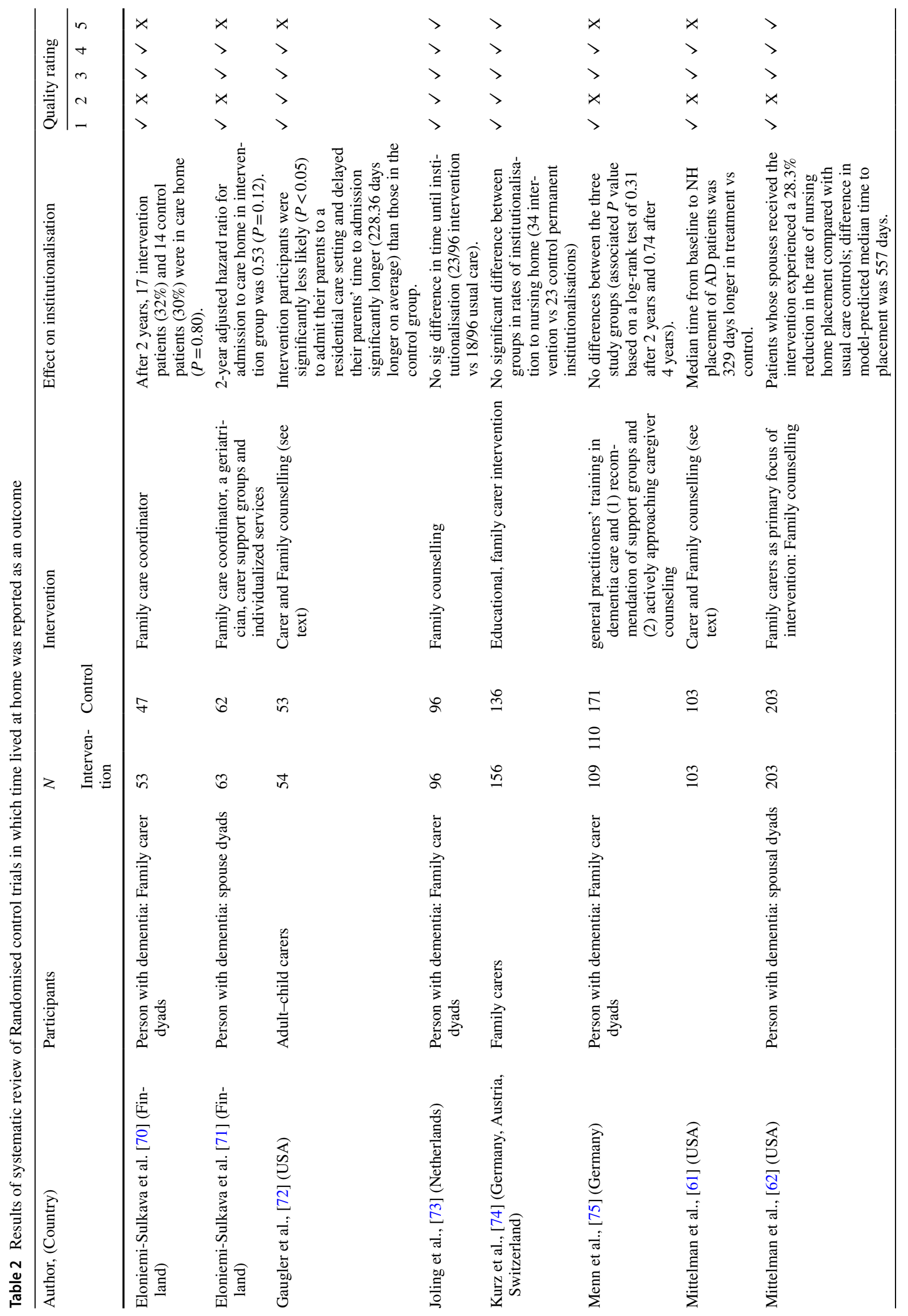


strategies, and referral and linkage to resources/services. An interventionist takes a coordination role consistent with dementia case management. Relative to participants receiving the control intervention, intervention participants were less likely to permanently leave their home or die over 18 months and remained at home for longer (mean difference: 51 days) [49]. Benefits were sustained over 26 months: intervention participants were less likely to transition from home and remained at home longer than control participants (median difference: 288 days).

The New York University Spouse Caregiver Intervention (NYUCI) comprises two individual and four family counselling sessions tailored to each carer's specific situation, encouragement of weekly support group participation and ad hoc telephone counselling. Counselling session content was determined by the needs of each caregiver and their family and could include behavioural management and improving family communication. The person with dementia did not attend sessions [61, 62]. Intervention content maps to relational and recovery and family carer-focussed approaches and, because content was flexible, it was possible that other domains were covered. Care strategies used were needs-based and family carerfocussed. There was an element of dementia case management through availability of ad hoc, post-intervention support for carers. Intervention group care recipients stayed at home longer, relative to the control group. The median difference in time to nursing home placement was 557 days [61, 62].

Gaugler adapted the NYUCI intervention for adult-child carers of people living with dementia [63] and reported that control-group care recipients were more likely to enter an assisted living or residential care setting than those in the treatment group. Caregivers in the intervention condition were significantly more likely to delay residential care placement of parents compared with controls. The mean time from baseline to residential care admission for parents of adult children in the intervention condition was 972 days, compared with 743 days in the control group.

\section{Expert consultation and Model development}

CC synthesised evidence from reviews and the expert reference group to develop a theoretical model of independence at home for people living with dementia, which was then agreed and finalised in consultation with co-authors. Figure 3 shows the final model. This includes the ten values and approaches that should underpin support for people living with dementia: (1) Care should be compassionate and be centred around the person living with dementia, their important relationships and family carers. (2) Care decisions and strategies should balance often conflicting needs to consider both the autonomy and the safety of the person living 


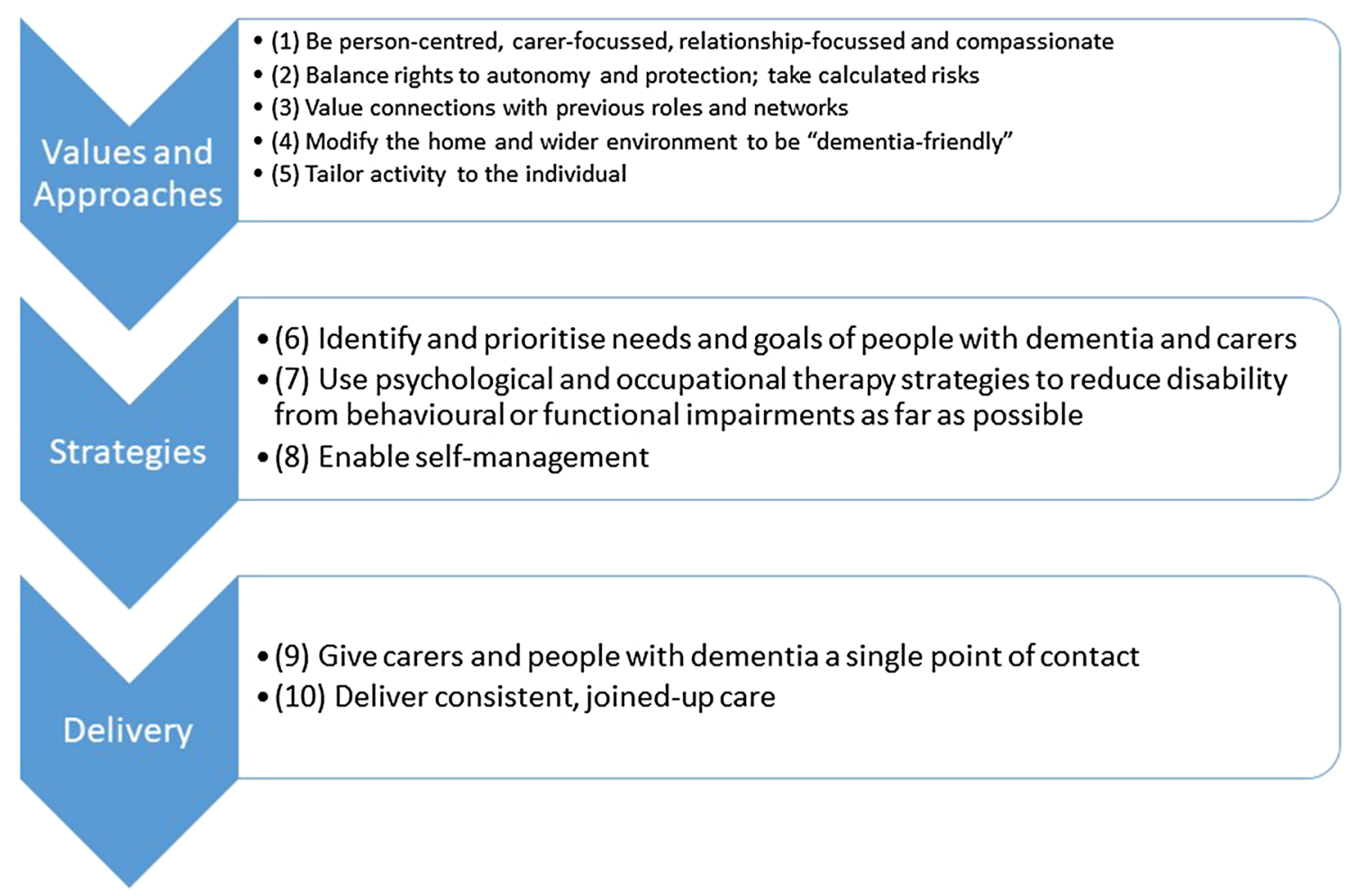

Fig. 3 NIDUS theoretical model of independence at home

with dementia. Calculated risks can allow more freedom and independence. [3] A focus on continued connections with earlier social networks and roles is important, as these are part of a person's identity. (4) The home and wider environment should be as dementia-friendly as possible. (5) Activities and plans should be tailored to the individual.

The care strategies that these values and approaches inform should be: [6] developed around the needs and goals of the person living with dementia and their family carers. [7] Psychological and occupational therapy strategies used to reduce disability from behavioural or functional impairments as far as possible and [8] self-management should be supported and. These care strategies should be delivered within a service: [9] for which family carers and people with dementia have a single point of contact. This could, for example be a case manager or General Practitioner; and that provides consistent, joined up care.

\section{Discussion}

The new model is theoretically informed, aligned with RCT evidence, and has been shaped by personal, clinical and academic perspectives. It incorporates the values and approaches integral to good quality dementia care as well as care strategies and service models likely to deliver these. People living with dementia and family carers are at the centre of our model. Their wellbeing, rights, dignity, needs and goals should inform what care is delivered and how. Care needs to be accessible; family carers and people with dementia need a clear point of contact to support them in managing needs as they arise. This point of contact can monitor the care delivered, ensuring it conforms to the values and approaches that support people to live well with dementia. Our model proposes that the home and wider community should be dementia friendly, and thus extends beyond the realm of clinical to social and community interventions.

Two interventions successfully increased time people with dementia lived at home: the Maximizing Independence at Home (MIND) and New York University Spouse Caregiver Interventions. We explored how the components of these interventions mapped onto our emerging theoretical model. These collectively encompassed the core values included in our final model. The similarities between findings from our theory-based and RCT-based review, and expert opinion supports face validity to our model.

Our model focuses on how people are supported to live well with dementia in their own homes. Essentially, we have developed a model of quality of care at home, though findings resonate with literature on quality of life in dementia and of the subjective experience of living well with dementia. Models of quality of life additionally include life events and challenges. Interestingly, in the IDEAL study, the largest study to date of living well with dementia, domains of psychological 
characteristics and psychological health (e.g., personality, optimism, loneliness, depression) most strongly predicted measures of living well.

\section{Limitations}

Our model was developed from a synthesis of theoretical models with a range of foci often with poorly defined constructs: living well, with life quality, with better functioning or longer at home. Our scoping review was deliberately broad and not all components included have a strong evidence base. For some model components, such as person-centred care, we find it hard to envisage how their efficacy in improving the lives of people living at home with dementia could be directly, ethically and empirically tested. For others there was equivocal evidence. A Cochrane review of care management interventions in dementia found heterogeneity in interventions and equivocal results, with some indication of delay to care home placement over 18 months [52]. Two care models (consumerled and integrated-care models) that we identified in our theoretical review were not included in the final model because there was a lack of evidence that they were directly associated with good quality care, though they may facilitate it.

We did not include models explaining how family carers of people with dementia cope and can be supported, for example the stress health process framework [64], unless they directly addressed how and whether people with dementia were able to live well and for longer at home. Other work was excluded because it did not specifically consider dementia. For example, we reported limited evidence for restorative models of home care in dementia as most trials exclude people living with dementia [65].

We only systematically reviewed RCTs regarding the outcome of time lived at home. This is an indicator of living well at home, but quality of the lived experience is important too. We did not meta-analyse outcomes due to heterogeneity of populations and outcomes and because our purpose was to identify effective interventions to inform development of our model. Of all the included studies in our RCT systematic review, only the MIND RCT included a racially diverse population (29\% non-white). People from Black and minority ethnic backgrounds tend to access services less and are less likely to move to a care home [66], so there may be cultural differences in optimal models of home support.

\section{Conclusions}

Our theoretical model describes values, care strategies and service models that can be used in the design of future interventions to enable people with dementia to live well and for longer at home.
Funding This work forms the first phase of the NIDUS (New Interventions in Dementia Study), which is hosted within the Alzheimer's Society Centre of Excellence for Independence at home (Centre of Excellence grant 330).

\section{Compliance with ethical standards}

Conflict of interest On behalf of all authors, the corresponding author states that there is no conflict of interest.

Open Access This article is distributed under the terms of the Creative Commons Attribution 4.0 International License (http://creativeco mmons.org/licenses/by/4.0/), which permits unrestricted use, distribution, and reproduction in any medium, provided you give appropriate credit to the original author(s) and the source, provide a link to the Creative Commons license, and indicate if changes were made.

\section{References}

1. Prince M, Bryce R, Albanese E, Wimo A, Ribeiro W, Ferri CP (2013) The global prevalence of dementia: a systematic review and metaanalysis. Alzheimer's Dement 9(1):63-75

2. Prince M, Knapp M, Guerchet M, McCrone P, Prina M, ComasHerrera A et al (2014) Dementia UK: update. Alzheimer's Society, London

3. Lord K, Livingston G, Robertson S, Cooper C (2016) How people with dementia and their families decide about moving to a care home and support their needs: development of a decision aid, a qualitative study. BMC Geriatr 16(1):68

4. Lin SY, Lewis FM (2015) Dementia friendly, dementia capable, and dementia positive: concepts to prepare for the future. Gerontologist 55(2):237-244

5. Office PM (2015) Prime Minister's challenge on dementia 2020. English Government, London

6. Camberg LC, Smith NE, Beaudet M, Daley J, Cagan M, Thibault G (1997) Discharge destination and repeat hospitalizations. Med Care 35(8):756-767

7. Gaugler JE, Yu F, Krichbaum K, Wyman JF (2009) Predictors of nursing home admission for persons with dementia. Med Care 47(2):191-198

8. Manthorpe J, Iliffe S, Samsi K, Cole L, Goodman C, Drennan V et al (2010) Dementia, dignity and quality of life: nursing practice and its dilemmas. Int J Older People Nurs 5(3):235-244

9. Woods B (1999) Promoting well-being and independence for people with dementia. Int J Geriatr Psychiatry 14(2):97-105 (Discussion-9)

10. Arksey H, O'Malley L (2005) Scoping studies: towards a methodological framework. Int J Soc Res Methodol 8(1):19-32

11. Mukadam N, Cooper C, Livingston G (2011) A systematic review of ethnicity and pathways to care in dementia. Int $\mathbf{J}$ Geriatr Psychiatr 26(1):12-20

12. Cooper C, Ketley D, Livingston G (2014) Systematic review and meta-analysis to estimate potential recruitment to dementia intervention studies. Int J Geriatr Psychiatr 29(5):515-525

13. Downs M, Lord K (2017) Person-centered dementia care in the community; a perspective from the United Kingdom. J Gerontol Nurs 43(8):11-17

14. Rothera I, Jones R, Harwood R, Avery AJ, Fisher K, James V et al (2008) An evaluation of a specialist multiagency home support service for older people with dementia using qualitative methods. Int J Geriatr Psychiat 23(1):65-72 
15. McIntyre M (2003) Dignity in dementia: person-centered care in community. J Ageing Stud 17:11

16. Brooker D (2006) Person-centred dementia care: making services better. Jessica Kingsley Publishers, London

17. Chung PYF, Ellis-Hill C, Coleman P (2017) Supporting activity engagement by family carers at home: maintenance of agency and personhood in dementia. Int J Qual Stud Health Well-being. 12(1): 1267316

18. Smebye KL, Kirkevold M (2013) The influence of relationships on personhood in dementia care: a qualitative, hermeneutic study. BMC Nurs 12(1):29

19. Kontos P (2005) Embodied selfhood in Alzheimer's disease: rethinking person-centered care. Dementia 4(4):17

20. Zwijsen SA, Niemeijer AR, Hertogh CM (2011) Ethics of using assistive technology in the care for community-dwelling elderly people: an overview of the literature. Aging Ment Health 15(4):419-427

21. Behuniak SM (2010) Toward a political model of dementia: power as compassionate care. J Aging Stud 24:9

22. Manthorpe J, Samsi K (2016) Person-centered dementia care: current perspectives. Clin Interv Aging 11:1733-1740

23. Cahill S (2018) Dementia and human rights. Policy Press, Bristol

24. Smebye KL, Kirkevold M, Engedal K (2016) Ethical dilemmas concerning autonomy when persons with dementia wish to live at home: a qualitative, hermeneutic study. BMC Health Serv Res 16:21

25. Tranvag O, Petersen KA, Naden D (2013) Dignity-preserving dementia care: a metasynthesis. Nurs Ethics 20(8):861-880

26. Daley S, Newton D, Slade M, Murray J, Banerjee S (2013) Development of a framework for recovery in older people with mental disorder. Int J Geriatr Psychiatr 28(5):522-529

27. Perkins R, Hill L, Daley S, Chappell M, Rennison J (2018) Continuing to be me-Recovering a life with a diagnosis of dementia. Nottingham: ImROC, Implementing Recovery through Organisational Change. https://imroc.org/resources/12-continuing-recov ering-life-diagnosis-dementia/

28. Menne HL, Kinney JM, Morhardt DJ (2002) Trying to continue to Do as Much as They Can Do: theoretical insights regarding continuity and meaning making in the face of dementia. Dementia 1(3): 15

29. Woodbridge R, Sullivan MP, Harding E, Crutch S, Gilhooly KJ, Gilhooly M et al (2018) Use of the physical environment to support everyday activities for people with dementia: a systematic review. Dementia (London) 17(5):533-572

30. Hoppes S, Davis LA, Thompson D (2003) Environmental effects on the assessment of people with dementia: a pilot study. Am J Occup Ther 57(4):396-402

31. Kovach CR (2000) Sensoristasis and imbalance in persons with dementia. J Nurs Scholarsh 32(4):379-384

32. Kolanowski AM, Fick DM, Clare L, Therrien B, Gill DJ (2010) An intervention for delirium superimposed on dementia based on cognitive reserve theory. Aging Ment Health 14(2):232-242

33. Callahan CM, Boustani MA, Schmid AA, LaMantia MA, Austrom MG, Miller DK et al (2017) Targeting functional decline in alzheimer disease: a randomized trial. Ann Intern Med 166(3):164-171

34. Caron CD, Ducharme F, Griffith J (2006) Deciding on institutionalization for a relative with dementia: the most difficult decision for caregivers. Can J Aging 25(2):193-205

35. Hurley AC, Gauthier MA, Horvath KJ, Harvey R, Smith SJ, Trudeau S et al (2004) Promoting safer home environments for persons with Alzheimer's disease. The Home Safety/Injury Model. J Gerontol Nurs. 30(6):43-51

36. Brodaty H, Gresham M, Luscombe G (1997) The Prince Henry Hospital dementia caregivers' training programme. Int J Geriatr Psychiatr 12(2):183-192
37. Gresham M, Heffernan M, Brodaty H (2018) The Going to Stay at Home program: combining dementia caregiver training and residential respite care. Int Psychogeriatr 30:1697-1706

38. Livingston G, Manela M, O'Keeffe A, Rapaport P, Cooper C, Knapp M, King D, Romeo R, Walker Z, Hoe J, Mummery C, Barber J (2019) Clinical effectiveness of the START (STrAtegies for RelaTives) psychological intervention for family carers and the effects on the cost of care for people with dementia: 6-year follow-up of a randomised controlled trial. Br J Psychiatry 12:1-8. https://doi.org/10.1192/bjp.2019.160

39. Bunn F, Goodman C, Pinkney E, Drennan VM (2016) Specialist nursing and community support for the carers of people with dementia living at home: an evidence synthesis. Health Soc Care Commun 24(1):48-67

40. Gaugler JE, Kane RL, Kane RA, Newcomer R (2005) Unmet care needs and key outcomes in dementia. J Am Geriatr Soc 53(12):2098-2105

41. Scholzel-Dorenbos CJ, Meeuwsen EJ, Olde Rikkert MG (2010) Integrating unmet needs into dementia health-related quality of life research and care: introduction of the Hierarchy model of needs in dementia. Aging Ment Health 14(1):113-119

42. Rockwood K, Graham JE, Fay S (2002) Goal setting and attainment in Alzheimer's disease patients treated with donepezil. J Neurol Neurosurg Psychiatr 73(5):500-507

43. Amella EJ, Batchelor-Aselage MB (2014) Facilitating ADLs by caregivers of persons with dementia: the $\mathrm{C} 3 \mathrm{P}$ model. Occup Ther Health Care 28(1):51-61

44. Beck C, Heacock P, Rapp CG, Mercer SO (1993) Assisting cognitively impaired elders with activities of daily living. Am J Alzheimer's Dis Dement 8(6):9

45. Graff C (2006) How can occupational therapy improve the daily performance and communication of an older patient with dementia and his primary caregiver? Dementia 5(4):29

46. Laakkonen ML, Kautiainen H, Holtta E, Savikko N, Tilvis RS, Strandberg TE et al (2016) Effects of self-management groups for people with dementia and their spouses-randomized controlled trial. J Am Geriatr Soc 64(4):752-760

47. Martin F, Turner A, Wallace LM, Bradbury N (2013) Conceptualisation of self-management intervention for people with early stage dementia. Eur J Ageing 10(2):75-87

48. Cabin WD (2008) Moving toward Medicare home health coverage for persons with Alzheimer's disease. J Gerontol Soc Work 51(1-2):77-86

49. Samus QM, Johnston D, Black BS, Hess E, Lyman C, Vavilikolanu A et al (2014) A multidimensional home-based care coordination intervention for elders with memory disorders: the maximizing independence at home (MIND) pilot randomized trial. Am J Geriatr Psychiatr 22(4):398-414

50. Banerjee S, Wittenberg R (2009) Clinical and cost effectiveness of services for early diagnosis and intervention in dementia. Int $\mathrm{J}$ Geriatr Psychiatr 24(7):748-754

51. Banerjee S, Willis R, Matthews D, Contell F, Chan J, Murray J (2007) Improving the quality of care for mild to moderate dementia: an evaluation of the croydon memory service model. Int $\mathbf{J}$ Geriatr Psychiatr 22(8):782-788

52. Reilly S, Miranda-Castillo C, Malouf R, Hoe J, Toot S, Challis D et al (2015) Case management approaches to home support for people with dementia. Cochrane Database Syst Rev 1:CD008345

53. Thyrian JR, Hertel J, Wucherer D, Eichler T, Michalowsky B, Dreier-Wolfgramm A et al (2017) Effectiveness and safety of dementia care management in primary care: a randomized clinical trial. JAMA Psychiatr 74(10):996-1004

54. Goeman D, Renehan E, Koch S (2016) What is the effectiveness of the support worker role for people with dementia and their carers? A systematic review. BMC Health Serv Res 16:285 
55. Khanassov V, Vedel I, Pluye P (2014) Case management for dementia in primary health care: a systematic mixed studies review based on the diffusion of innovation model. Clin Interv Aging 9:915-928

56. MacNeil Vroomen J, Bosmans JE, van de Ven PM, Joling KJ, van Mierlo LD, Meiland FJ et al (2015) Community-dwelling patients with dementia and their informal caregivers with and without case management: 2-year outcomes of a pragmatic trial. J Am Med Dir Assoc 16(9):800-e1

57. Renehan E, Goeman D, Koch S (2017) Development of an optimised key worker framework for people with dementia, their family and caring unit living in the community. BMC Health Serv Res 17(1):501

58. Low LF, Fletcher J (2015) Models of home care services for persons with dementia: a narrative review. Int Psychogeriatr IPA 27(10):1593-1600

59. Kohler L, Meinke-Franze C, Hein J, Fendrich K, Heymann R, Thyrian JR et al (2014) Does an interdisciplinary network improve dementia care? Results from the IDemUck-study. Curr Alzheimer Res 11(6):538-548

60. Evans S, Fear T, Means R, Vallelly S (2007) Supporting independence for people with dementia in extra care housing. Dementia 6(1):6

61. Mittelman MS, Ferris SH, Shulman E, Steinberg G, Levin B (1996) A family intervention to delay nursing home placement of patients with Alzheimer disease: a randomized controlled trial. J Am Med Assoc 276(21):1725-1731

62. Mittelman MS, Haley WE, Clay OJ, Roth DL (2006) Improving caregiver well-being delays nursing home placement of patients with Alzheimer disease. Neurology 67(9):1592-1599

63. Gaugler JE, Reese M, Mittelman MS (2013) Effects of the NYU Caregiver Intervention-Adult Child on residential care placement. The Gerontologist. 53(6):985-997

64. Levesque L, Gendron C, Vezina J, Hebert R, Ducharme F, Lavoie JP et al (2002) The process of a group intervention for caregivers of demented persons living at home: conceptual framework, components, and characteristics. Aging \& Mental Health. 6(3):239-247

65. Cooper C, Cenko B, Dow B, Rapaport P (2017) A systematic review evaluating the impact of paid home carer training, supervision, and other interventions on the health and well-being of older home care clients. Int Psychogeriatr IPA 29(4):595-604

66. Cooper C, Tandy AR, Balamurali TBS, Livingston G (2010) A systematic review and meta-analysis of ethnic differences in use of dementia treatment, care, and research. Am J Geriatr Psychiatr 18(3):193-203
67. Boustani MA, Sachs GA, Alder CA, Munger S, Schubert CC, Guerriero Austrom $M$ et al (2011) Implementing innovative models of dementia care: the healthy aging brain center. Aging Ment Health 15(1):13-22

68. Callahan CM, Boustani MA, Unverzagt FW, Austrom MG, Damush TM, Perkins AJ et al (2006) Effectiveness of collaborative care for older adults with Alzheimer disease in primary care: a randomized controlled trial. JAMA 295(18):2148-2157

69. Black BS, Johnston D, Rabins PV, Morrison A, Lyketsos C, Samus QM (2013) Unmet needs of community-residing persons with dementia and their informal caregivers: findings from the maximizing independence at home study. J Am Geriatr Soc 61(12):2087-2095

70. Eloniemi-Sulkava U, Notkola IL, Hentinen M, Kivela SL, Sivenius J, Sulkava R (2001) Effects of supporting community-living demented patients and their caregivers: a randomized trial. J Am Geriatr Soc 49(10):1282-1287

71. Eloniemi-Sulkava U, Saarenheimo M, Laakkonen ML, Pietila M, Savikko N, Kautiainen H et al (2009) Family care as collaboration: effectiveness of a multicomponent support program for elderly couples with dementia. Randomized controlled intervention study. J Am Geriatr Soc 57(12):2200-2208

72. Gaugler JE, Reese M, Mittelman MS (2013) Effects of the NYU caregiver intervention-adult child on residential care placement. Gerontologist 53(6):985-997

73. Joling KJ, van Marwijk HW, van der Horst HE, Scheltens P, van de Ven PM, Appels BA et al (2012) Effectiveness of family meetings for family caregivers on delaying time to nursing home placement of dementia patients: a randomized trial. PLoS One 7(8):e42145

74. Kurz A, Wagenpfeil S, Hallauer J, Schneider-Schelte H, Jansen S (2010) Evaluation of a brief educational program for dementia carers: the AENEAS study. Int J Geriatr Psychiatry 25(8):861-869

75. Menn P, Holle R, Kunz S, Donath C, Lauterberg J, Leidl R et al (2012) Dementia care in the general practice setting: a cluster randomized trial on the effectiveness and cost impact of three management strategies. Value Health 15(6):851-859

76. Nobili A, Riva E, Tettamanti M, Lucca U, Liscio M, Petrucci B et al (2004) The effect of a structured intervention on caregivers of patients with dementia and problem behaviors: a randomized controlled pilot study. Alzheimer Dis Assoc Disord 18(2):75-82

77. Teri L, Gibbons LE, McCurry SM, Logsdon RG, Buchner DM, Barlow WE et al (2003) Exercise plus behavioral management in patients with Alzheimer disease: a randomized controlled trial. JAMA 290(15):2015-2022

\section{Affiliations}

\section{Kathryn Lord ${ }^{1}$. Jules Beresford-Dent ${ }^{1} \cdot$ Penny Rapaport ${ }^{2} \cdot$ Alex Burton $^{2} \cdot$ Monica Leverton $^{2} \cdot$ Kate Walters $^{3}$. lain Lang ${ }^{4} \cdot$ Murna Downs $^{1}$. Jill Manthorpe ${ }^{5} \cdot$ Sue Boex ${ }^{6} \cdot$ Joy Jackson $^{6} \cdot$ Margaret Ogden $^{6} \cdot$ Claudia Cooper $^{2} \mathbb{C}$}

\author{
Kathryn Lord \\ K.Lord1@bradford.ac.uk \\ Penny Rapaport \\ p.rapaport@ucl.ac.uk \\ Alex Burton \\ a.burton@ucl.ac.uk \\ Monica Leverton \\ monica.leverton.17@ucl.ac.uk
}

Kate Walters

k.walters@ucl.ac.uk
Iain Lang

i.lang@exeter.ac.uk

Murna Downs

m.downs@bradford.ac.uk

Jill Manthorpe

j.manthorpe@kcl.ac.uk

Sue Boex

suemboex@gmail.com

Joy Jackson

j4kjackson@gmail.com 
1 Faculty of Health Studies, Centre for Applied Dementia Studies, Horton A Building, Richmond Road, Bradford BD7 1DP, UK

2 Division of Psychiatry, University College London, 6th Floor Maple House, Tottenham Court Road, London W1T 7NF, UK

3 Department of Primary Care and Population Health, University College London, Rowland Hill Street, London NW3 2PF, UK
4 South Cloisters, University of Exeter, St Luke's Campus, Heavitree Road, Exeter EX1 2LU, UK

5 Social Care Workforce Research Unit, King's College London, London WC2R 2LS, UK

6 Alzheimer's Society Research Network Volunteer, London, UK 